\title{
Political Cartoons in 1946 Turkish Elections
}

\author{
Baki Can \\ Ege University, Faculty of Communication, Izmir, Turkey
}

1946 elections retain a different part and significance by many aspects. Certainly, 1946 elections were not the only significant election in Turkish political history. However, 1946 elections indicate a crossroad, a milestone. 1946 elections express an important stage in Turkish political history as of transition stages from Selçuklu to principalities, from principalities to Ottoman State, from Ottoman State to Republic. Therefore it is one of the most important exchanges.

Transition to multiparty system can be considered not with 1946 elections, but with the establishment of National Development Party (MKP). As a matter of fact, two distinct parties were established between 1923 and 1944; both of them were suppressed by the moderation of the council of ministers (Tuncer, 2003). On the other hand, the first party in the multiparty system period is the National Development Party, established on July 18, 1945 (MKP). As for Democrat Party (DP), it was established on January 7, 1946 following MKP (Tuncer, 2003).

The significant part of 1946 elections with regards to this study of ours is that, it must be rather hard to decide electing the party to govern the country, for a mass, which was unaware of even imagining what the authority of electing one out of multiple until that day. At this point the role of mass media had been extensive in addition to messages received directly and via threshold level through face to face communication.

\section{Introduction}

One of most important political mass media currently is the electronic media. Thus, elections are as well called "electronic democracy" (Streek, 1997). Before the diffusion of the internet, influence of TV was extensive (Can, 1999). In our opinion, even though some researches were done on this subject, it would be early to answer the question as to whether the internet with TV or the internet by itself is more effective. However it would not take even a few years to make an absolute statement. 
There were two mass communication devices of 1946 elections period. These were radios and the newspapers. Radio was the monopoly in the foreground of the state. The government, meaning state at some point, could use the radio. The ruling party did not allow the opposing parties to propagandize on the radio. Radio was spread from large city centres to villages at the province area. Newspapers on the other hand, could be sold in main centres. A portion of the public could only read in Ottoman letters, and another portion could only read in Latin letters. A portion did not even read and write. In Turkey, as well as the whole globe, political advertisements have been utilized in recent years and been effective. However in 1946 and in many following elections, it was impossible to talk about political advertisements (Can, 2006) or even its name.

In spite of these challenges in using these communication devices, the public was in tight communication and interaction in their own regions. In other words, face to face communication was effective. It had been same on electoral matters. The newspapers purchased from centres were read by the literate ones, pictures and cartoons were told in relation to the texts, and even interpreted.

Until the beginning period of transition to multiparty system, newspapers were proceeding as the publication organ of the ruling party. There were newspapers and journalists who became “opposing" after quitting CHP partisanship as well as members of the parliament who quit CHP.

We consider that cartoons had a significant part in teaching public the multiparty system, democracy, opposition, government, and function of voter etc. and influencing them on these subjects.

\section{Parties Attending Elections and Results}

Six parties attended to the July 21, 1946 elections. These were, Republican People's Party (CHP), Democrat Party (DP), Liberal Democrat Party (LDP), Turkey Labours and Farmers Party (TIÇP), and Only for Country Party (YVIP). DP could not enter these elections in 16 cities. These cities were: Ağrı, Bingöl, Bitlis, Çorum, Diyarbakır, Gümüşhane, Hakkari, Kars, Kırşehir, Malatya, Mardin, Muş, Niğde, Rize, Siirt and Van. 
The number of 455 parliament members had been increased to 465 with a decision before the elections. After the elections, out of 465 seats, 397 went to CHP, 61 to DP and seven to independents. Yet, because two parliament member candidates of DP and 2 independent candidates were presented and elected from two election region, member count in the parliament was 462 instead of 465 . In this case, parties appeared in the parliament as CHP 397, DP 58 and independents six. Three seats remained unfilled (Tuncer, 2003). Detailed information covering Turkey was not attained anywhere including not only TBMM library. Besides, TUIKK library some news appeared after the elections in newspapers indicate that there were some question marks regarding the results. For instance, the news published in July 24, 1946 dated Cumhuriyet newspaper as 'the votes acquired by H.P. in Mudurnu appeared 500 more than the voters' and other similar news bring out some question marks to the mind.

\section{Methodology}

The cartoons published in newspapers before 1946 elections were coded by two communication specialists. The credibility average between coders increased +99 for questions where tangible answers were demanded. It is +93 for questions where personal interpretation is necessitated. Mean credibility average is +96 . Every cartoon is coded according to 22 questions. The cartoons irrelevant to elections were not evaluated. Questions were categorized in two groups. The first one is the one that is directly related to the structure of the cartoon. The ones in the other group are related to the political message that the cartoon is conveying. The subjects covering discourse analysis were tried not to get involved in at maximum level. The content analysis of the cartoons published in the newspapers before 1946 elections are processed according to the coding determined for the questions by the coders in these two main groups. Holsti's methodology (Holsti, 1969) is used for the content analysis.

\section{Elections}

1946 elections is the most important political turning point of the Republic history. Until 1946 the country had been ruled by Republic's People Party solely. Criticizing or defending this case is not our job. Since other parties were not aloud to be established, Republican People's Party entered the elections on its own. In fact, until 1946 elections, parties other than Republican People's Party were also established. However these parties were closed by the moderation of the Council of Ministers. 1946 elections are the first elections where other 
parties attended along with Republic's People Party. In this respect, what multi-party democracy was and how it functioned were not clarified in the minds of politicians, newspapers and public. That is why there was a "digestion difficulty" as expressed in the cartoon.

The greatest rival of ruling CHP was DP in 1946 elections. Most of the DP administrators were people who entered political life in CHP. A portion was the ones who head met politics the first time. CHP General President was the National Chief Ismet Inönü, the current president expressed by the newspaper. The government consisted of CHP parliament members. CHP provincial chairmen were functioning as governors of those provinces.

Parliament member candidates were announced in short notice prior to elections. This situation can be seen in newspaper news as well. For instance, the following were written on the first page of Cumhuriyet newspaper on various dates: on July 17, 1946, 'DP announced Izmir and Konya candidates'; on July 18, 'DP Istanbul, Ankara, Aydın, Manisa, Erzurum, Çankırı, Bilecik Bursa candidate lists are accepted by the party'; and on July 19, 'Public's Party also announced the candidate list yesterday. There are 162 new faces on the list; the other candidates are old parliament members'. Besides, we see that DP did not announce its candidates all at the same time.

In1946 elections open vote-secret count method was applied. In other words, the preferences were done in front of everybody during voting, and the votes were classified and counted in an environment where there were only attendants after voting.

The meetings at open squares assigned were at forefront as propaganda. Crowds of $40-50$ thousand people gathered in large cities were indicating the power of the parties. On the other hand, speaking on behalf of the party was only CHP's that was ruling. In many provinces, propagandizing on roads and open squares were banned by the military commission.

In our opinion, some situation and applications that sound odd today arouse from the process. We can see this in the phrase 'We swallowed this big bite (democracy), but the digestion is difficult!' related to the cartoon 'democracy while expecting for digestion' on the first page of Yeni Sabah Newspaper dated July 3, 1946. 


\section{Scope}

During June 21, 1946 elections, numerous national and local newspapers were being published. Out of these newspapers, we will be content analyzing the cartoons directly or indirectly related to elections in national newspapers Cumhuriyet, Son Posta, Vakit and Yeni Sabah. Akşam and Ulus newspapers were benefited for the agenda. Yet, cartoons directly or indirectly related to the elections were not found in the newspapers.

The total of cartoons we evaluated and selected as appropriate for coding is 86.34 of these were published in Cumhuriyet, five in Son Posta, nine in Vakit and 38 in Yeni Sabah newspapers. It has been observed that more than 86 cartoons were published in these newspapers. Yet, the rest is not in the content of our study since they are not related to elections. All cartoons related to the elections in these newspapers are at this total.

The general and elections related agendas of the period were attained from these newspapers. Akşam and Ulus newspapers come to forefront as agenda setters. Ulus newspaper is CHP's own publishing medium. The hints in these newspapers such as news, commentary, photography, as to which page it was placed, informs us about newspaper agenda in 1946 elections period. For both following agenda and selections of cartoons, we included the duration beginning from May until the end of July in our content.

Not all of the cartoons were coded according to all of the questions. The reason is that question not being appropriate for the related question, in other words, meaningless. Besides, some answers were not counted as a value among all answers. This is why 86 numbers could not be achieved for answers of some questions. For some the opposite is valid. With these, more than one of the answers is related to the question.

In order for us to comprehend what were in the agenda of newspapers in 1946 elections period, we examined the first pages of Cumhuriyet, Son Posta, Vakit and Yeni Sabah newspapers of which we examined the cartoons. Besides, we also considered necessary to examine the first page of Ulus newspaper because it was the corporation publishing medium of CHP (İnuğur, 1992) which had been ruling Turkiye since 1923. Though, it was not possible 
to mention any newspaper that did not praise CHP until prior to 1946 elections. But Ulus was different.

Among subject newspapers, we could not determine any other newspaper that is criticizing CHP, excluding Yeni Sabah. Yeni Sabah had a publishing policy that was constantly praising Democrat Party and criticizing CHP. Vakit newspaper was constantly praising CHP and criticizing Democrat Party. Cumhuriyet and Son Posta newspapers preferred following a rather midway. But they were not neglecting to bring CHP forefront sometimes even if it was in an indirect way. Humorists, in one party term (in spite of existing small critical glints) were defeated.

On July 21, 1946, meaning the elections day, six arrows were drawn as CHP's emblem in red above the articles on the first pages of Ulus and Vakit newspapers. In Vakit newspaper, the article "citizen, vote for CHP" was attracting attention. On July 21, Yeni Sabah newspaper symbolized CHP with positive adjectives and DP with negative ones, and afterward, wrote as "like one, chose the one you like". Ulus was explaining how to vote CHP as the only party it pointed out to the voter. Multiparty democracy and the existence of opposition were not even accepted.

If you would look at it in general, in our research from beginning of May until end of July, we can state that the largest space was covered with news and comments regarding July 21 elections on the first pages of the newspapers. We see that news and comments regarding achievements of the government appeared in second place, Paris conference in third place, firing of the atomic bomb in fourth place, hearing of the murder case in the court of Bolu in fifth place, various statements expressing the gladness of state authorities during the visit of Missouri the American ship in sixth place, and finally leaving the Twelve Islands to the Greeks.

\section{Political Cartoons}

From this point of view, we can state that political cartoons play significant roles in political attitudes and behaviours because the importance of political dreaming (Pekonen, 1990) is great for innovations in political structure attitudes. We believe that cartoons would have serious contributions in stage of dreaming or being able to dream. Thus, we can state that 
cartoons play important roles in building, changing political attitudes and orientating towards behaviour. Hence, newspaper cartoons would facilitate the adaptation of voters to multiparty system in an environment such as 1946 parliament member elections, where the education level of the voters are low, moreover literacy proportion is low and multi-party system was not even clearly known. Political cartoons are the very simple way of conveying the political messages. Political cartoons use the symbols which are known by society and for being more elucidative they use subtitles.

In fact, the word karikatür (cartoon in Turkish) is derived from the word caricare-caricatura in Italian, meaning exaggerating, enlarging. Whether it is political or daily or events concerning whole of the society, can be conveyed through cartoons either by condemning or by humorous description. There can be humour in condemning. That is why cartoon can also be defined as making humour by drawing (Selçuk, 1998).

The fact of cartoons being effective on human is undeniable. Furthermore, we can say that cartoons affect cultural and political attitudes and behaviours. Since cartoon is telling much by drawing little, it would be possible to convey the purpose to very large masses and influencing them by the given message because cartoon is a method of artistic messaging where certain emotions and desires are conveyed in a quick, simple and amusing way. Cartoons are suitable for developing comments and through which the cartoonist can easily reflect ideas and desires. It is possible to see these general characteristics in cartoons drawn on political subjects.

\section{The Contents of the Cartoons}

In 1946 elections, directly and indirectly elections related cartoons in newspapers were published in two distinct sizes. In elections period, 11 pieces of the totally 86 cartoons related to elections cover half a page, and 75 pieces of it cover a space smaller than a quarter space. This shows us that the $85 \%$ of analyzed cartoons are smaller than quarter of a page and $15 \%$ are half a page. Half a page ones were drawn and printed in colour, the ones smaller than quarter of a page is not drawn and printed in colour, but in black and white.

The coloured ones in half a page size are located on the upper part of the last page, and the black and white small cartoons are located at the bottom right corner of the first page. The 6 
pieces of half a page size cartoons were published in Cumhuriyet newspaper, six pieces were published in Vatan newspaper. No half a page cartoons at all were published in Son Posta and Yeni Sabah newspapers. In this case, five pieces of the nine cartoons in Vakit newspaper were half a page and in colour, and four pieces were small and in black and white. Six out of 34 cartoons in Cumhuriyet newspaper are half a page and in colour, 28 pieces are small and in black and white.

It can be stated that both cartoons were located in significant parts of the newspapers when we consider the route for utilization of the eyes during the process of glancing and reading. This condition shows us that the people competent for page set up of the subject newspapers, considered these cartoons important, thus they wanted them to be published in an attention attracting location.

When we look at the cartoons regarding their relation with the elections, we can see that they can be grouped under two topics. The cartoons analyzed are either directly or indirectly related to the elections. The numbers of cartoons related directly or indirectly to the elections are close to each other. 38 of the cartoons are directly related to the elections, 48 of them are indirectly related. Should we express in percentage, approximately $44 \%$ is directly and $56 \%$ is indirectly related to the elections.

There are also cartoons that were not directly or indirectly related to the elections, published in newspapers in this period. These are cartoons drawn in relation to social, economical, Turkish foreign policy and international issues. Among these, there are cartoons which indicate the roles in family, the process of international peace conference, encountered economical challenges, football team partiality, codes of social behaviour and the conversation between Turkish state governors and authorities of Missouri ship that was visiting Turkey at the time.

There is multiparty system in most of the cartoons. It has been determined that multiparty system was focused in $70 \%$ of the cartoons. There is an attention grabbing number among the rest as cartoons related to CHP in $19 \%$, DP in $7 \%$, MP in $3 \%$ and independents in $1 \%$. This indicates that concepts such as multiparty system, democracy, referring to public and similar were significantly considered important in newspapers. It has been comprehended that these newspaper cartoons had an educational and instructional function through a simple, sarcastic, 
ironic expression during the process of Turkish voters' learning these concepts. We see that the tendency of cartoons towards parties were neutral in vast majority. This ratio is approximately $68 \% .5 \%$ of cartoons are in negative tendency towards CHP, $6 \%$ are in positive tendency towards DP, $5 \%$ are in positive tendency towards CHP and $4 \%$ are in negative tendency to towards DP. According to the findings captured here, a remarkable difference was not detected regarding the tendencies towards parties among newspapers of differing publishing lines.

Among the answers for the question are you perceiving negative offense, we confronted a result different from the previous break down. Negative offense is not perceived in $41 \%$ of total of the cartoons. In $26 \%$ of the cartoons, negative offense is perceived to multiparty system. Of negative offense towards parties, $20 \%$ is towards CHP $9 \%$ towards DP and $3 \%$ towards MP.

The vast majority of the cartoons talk about parties and party members. The ratio of these is $73 \% .17 \%$ of the cartoons are about party opinions, and $10 \%$ are about party leaders. As is seen, party leaders are not at the forefront in cartoons. Although in newspaper news it is frequently emphasized that CHP is 'the parties of the National Chief and the Eternal Chief' and written articles about İnönü and Bayar, it is an attention grabbing condition for such rare appearance of these in cartoons.

Again, it is seen that cartoons appeal to emotions in vast majority. Approximately $74 \%$ of cartoons predominantly appeal to emotions. The percentage of cartoons in which rational message method is used is determined as $26 \%$. This shows that both cartoonists and newspaper readers are inclined to trading messages that are predominantly emotional. Certainly, this does not mean that the vast majority of the cartoons solely appeal emotions. It is seen that the predominant appeal style is emotional in these cartoons. Likewise, it is seen that emotions are appealed in lesser ratios in reasonable appeal styles. It is possible to see reasoning in the larger $74 \%$ slice, and emotional appeal in $26 \%$.

In cartoons where emotional appeal style is dominant, the predominant existence of negative emotions is drawing attention. It is seen that in $90 \%$ of the cartoons there is negative 
emotions and positive emotions in only $10 \%$. We believe that the abundance of the cartoons perceived in negative emotions shows that daily political developments are viewed negatively.

Of the cartoons where reasonable implications are predominant, the implication of vast majority is left to the readers. Since it also means to procure acceptance and persuasion through the internalization of the given message by leaving the implication to individuals through reasonable expression, we can state that cartoons take over such an effect. Where reasonable implication is left to the newspaper reader in $73 \%$ of cartoons, the reasonable implication is directly given in $27 \%$.

A non-proportional break down is seen by in terms of subject diversity. A single matter is discussed in $86 \%$; multiple matters are discussed in $14 \%$. This situation provides advantages both for the cartoonist and the reader. Thus, the comprehensibility and effect of each subject increases.

With the given message, we see that developing an attitude is at forefront in relation to the target of the cartoon and the expectation. As secondary, it is targeted to amuse and entertain. Parallel to the given message, the ratio of cartoons that target developing new attitude or enhancing the attitude is $56 \%$. Cartoons that target amusing and entertaining are $40 \%$ of total. Cartoons that directly stimulate action are $4 \%$. Here, the ratios of cartoons that target either developing attitude, entertaining and directly stimulating action are the attained dominant targets.

The messages that arouse emotions of fear in newspaper readers are very rare. Among all, the cartoons that do not arouse fear are $80 \%$. The ratio of messages that directly arouse emotions of fear is $15 \%$. The ones that indirectly arouse fear are $15 \%$.

As for the content of cartoons about transition to multiparty system, there is praising in only $5 \%$, direct praising in $4 \%$, open condemning in $17 \%$, and indirect condemning in $74 \%$. This indicates that newspapers do not favour transition to multi-party system much, moreover they approach it a negative attitude. However, it is attention grabbing for a high ratio of condemns such as $74 \%$ to be indirect. 
The parties come up front with their corporate identities. It is seen that corporate identities of parties are upfront in $63 \%$ of cartoons coded in this category. Party opinion comes upfront in $21 \%$ and party leaders in $17 \%$. It is believed that party leaders have always been in front of party corporate identities in subsequent electoral campaigns.

Multiparty system is at forefront in vast majority of the cartoons. Multiparty system is upfront in $91.5 \%$ and single party system is upfront in $8.5 \%$ of cartoons considered to be suitable for coding.

Again, vast majority of cartoons emphasize accomplishments and failures. The cartoons about party promises are way behind in number. Achievements and failures both in domestic politics and foreign politics are upfront in $78 \%$ and party promises are upfront in $22 \%$ of the cartoons coded in this matter.

As we take a look at the scope of discussed matters in cartoons, nearly all results are close to each other. A specific, tangible matter is discussed in $48 \%$ of cartoons coded. Not only a single matter but multiple matters are emphasized in the remaining $52 \%$.

Smoking cigarettes and cigars and drinking alcohol as bad habits also take part in cartoons. It attracts our attention where bad habit related symbols appear with state governors in the cartoons to whom positive and negative images are charged.

$8 \%$ of cartoons consist only of drawings. There is both drawing and text in the remaining $92 \%$. It is used, a symbol other than human in $20 \%$, political symbols besides human in $40 \%$, and both political and other symbols besides human in $40 \%$ of the cartoons.

It is drawn only politicians in $27 \%$, only public in $49 \%$ and both politicians and public in $24 \%$ of the cartoons.

It is predominantly seen that positive and negative images are charged to the politician both in the drawing and the text. The ratio of this charging both in the drawing and the text is found as $92 \%$. 


\section{Summary and Conclusion}

1946 elections are the first multiparty system elections in Turkish Republic History. In proceeding years two distinct parties were founded. However these were closed due to the moderation of the council of ministers. CHP who ruled the country as the only party permitted other parties to enter the political stage in the elections. National and international developments played triggering roles in this process.

There were two mass media of the period. One was the radio and the other was the newspaper. The radio was in the state monopoly and it was not permitted for the opposition to use it during these elections. It could only be propagandized for CHP on the radio. The public could be informed of the existence and activities of the opposition only through face to face communication and newspapers. The low ratio of public literacy increased the function of cartoons which was the method of saying much by drawing little.

Cartoons were selected from four distinct newspapers. Of these newspapers, 86 pieces of nearly 110 cartoons were found to be relevant to the elections and content analysis was done. 75 of these cartoons were published at the bottom right corner on the first page in black and white covering a small space, and 11 were on the upper corner on the last page in colour, covering half a page. $92 \%$ of cartoons consist of both drawing and text.

$44 \%$ of cartoons are directly related to the elections and $56 \%$ are indirectly related. Multiparty system is in focus of cartoons by $70 \%$. As for the sympathy for parties, the approach is neutral in $63 \%$. The ratio of negative offense to multiparty system is $26.4 \%$. Parties and partisans appear as the main theme discussed. $73 \%$ appeal emotions in accordance with the political state and structure of the voter. $90 \%$ of these appeals are negative. Reasonable implications are left to the reader by $73 \%$. Attitude change is targeted in $55 \%$. A direct or indirect fear appeal is not sensed in $80 \%$. Transition to multiparty system is condemned indirectly by $74 \%$ predominance. Multiparty system is discussed in $91.5 \%$. More than one matter is discussed in $52 \%$. It is drawn only people from public in $49 \%$.

All of these indicate that cartoons were also used in conveying messages to public parallel to the newspaper news and comments. We see this in the content of the cartoons and political structure of the time. Additionally, we come to the conclusion that, cartoons were used as a 
very important messaging media in such elections conducted during transition to multiparty system.

On the other hand, when we look at all of the cartoons, we can state that each drawing and text has a function of completing each other, furthermore intensifying one another meaning and comprehensibility.

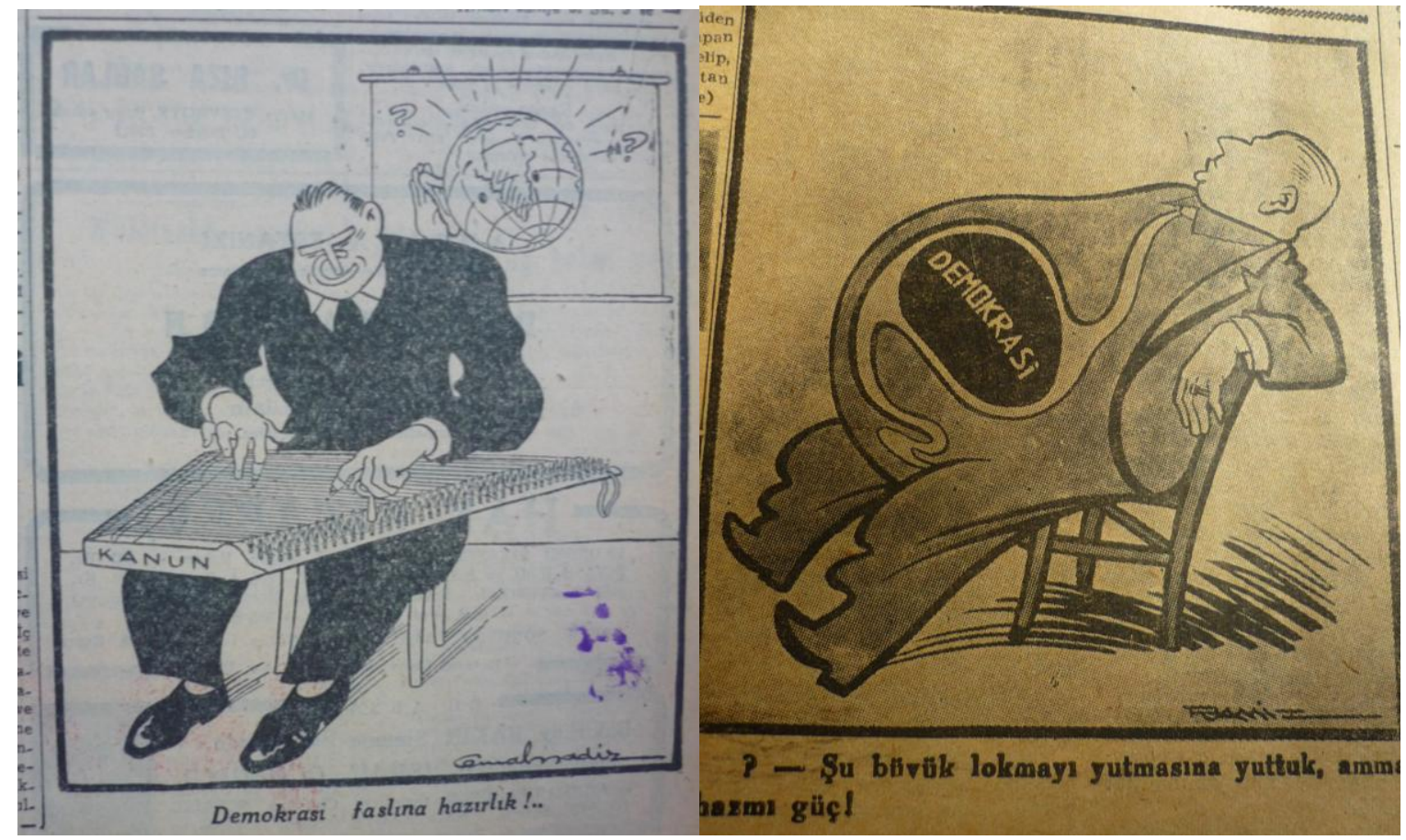

*“Preparation for democracy!..”

**“"We swallowed this big bite, but the digestion Hard!"

*Cumhuriyet Newspaper, drawn by Cemal Nadir, June 8, 1946

**Yeni Sabah Newspaper, drawn by Ramiz , July 3, 1946

\section{References}

Aziz, A.(2007). Siyasal Iletişim. Ankara, Turkey: Nobel Yayın Dağıtım.

Can, B. (2006). Persuading Voters and Political Advertising in Turkey, L.L Kaid \& C.H Bacha (e.d) The Sage Hand Book of Political Advertising (387-398) Thousand Oaks. Ca: Sage Publications.

Can, B. (1999). Television and Electroral Success in Turkey, L.L Kaid (ed.) Television and Politics in Evolving European Democracies (171-185) New York: Nova.

Çeviker, T.(2010). Karikaturkiye. Istanbul, Turkey: NTV yayinlari. 
Erdem, M. Kültür, Siyaset ve Karikatür: Temsil Güç ve Direniş, Medya ve Siyaset C.1. Izmir, Turkey: Ege Üniversitesi Iletişim Fakültesi.

Holsti, Ole R. (1969). Content Analysis for the Social Sciences and Humanities. Massachusetts: Addison-Mesley Publishing.

İnuğur, M.N. (1992). Türk Basın Tarihi. Istanbul, Turkey: Istanbul Gazeteciler Cemiyeti.

Peleonen, K. (1990). Symbols and Politics as Culture in the Modern Situation: the Problem and Prospects of the "New", J.R Gibbins (ed.) Contemporary Political Culture (127144) London: Sage Publications.

Selçuk, T. (1998). Grafik Mizah. Istanbul, Turkey: Iris Yayınları.

Street, J. Remote Control? Politics, Technology and "Electronic Democracy"

European Journal of Communication (pp.12-1, 27-42).

Tuncer, E.(2003). Osmanlı'dan Günümüze Seçimler. Ankara,Turkey: Toplumsal Ekonomik Siyasal Araştirmalar Vakfı Yayınları. 